Portland State University

PDXScholar

\title{
Copper Thin-Film Dissolution/Precipitation Kinetics in Organic HF Containing Cleaning Solution
}

\author{
Nabil George Mistkawi \\ Portland State University \\ Makarem A. Hussein \\ Malgorzata Ziomek-Moroz \\ U.S. Department of Energy \\ Shankar B. Rananavare \\ Portland State University, ranavas@pdx.edu
}

Follow this and additional works at: https://pdxscholar.library.pdx.edu/chem_fac

Part of the Other Chemistry Commons

Let us know how access to this document benefits you.

\section{Citation Details}

Nabil G. Mistkawi, Makarem A. Hussein, Malgorzata Ziomek-Moroz, and Shankar B. Rananavare, "Copper Thin-Film Dissolution/Precipitation Kinetics in Organic HF Containing Cleaning Solution," J. Electrochem. Soc., 157(8), 801-805 (2010).

This Article is brought to you for free and open access. It has been accepted for inclusion in Chemistry Faculty Publications and Presentations by an authorized administrator of PDXScholar. Please contact us if we can make this document more accessible: pdxscholar@pdx.edu. 


\title{
Copper Thin-Film Dissolution/Precipitation Kinetics in Organic HF Containing Cleaning Solution
}

\author{
Nabil G. Mistkawi, ${ }^{\text {ab }}$ Makarem A. Hussein, ${ }^{\mathrm{b}}$ Malgorzata Ziomek-Moroz, ${ }^{\mathrm{c}}$ and \\ Shankar B. Rananavare ${ }^{\mathrm{a}, \mathrm{z}}$
}

${ }^{a}$ Department of Chemistry, Portland State University, Portland, Oregon 97207-0751, USA

${ }^{b}$ Intel Corporation, Hillsboro, Oregon 97123, USA

${ }^{c}$ U.S. Department of Energy, National Energy Technology Laboratory, Albany, Oregon 97321, USA

The corrosion behavior of electrochemically deposited copper thin films in deaerated and non-deaerated commercial cleaning solution containing HF has been investigated. Thin-film copper dissolution and reaction kinetics were investigated by monitoring $\mathrm{Cu}^{2+}$, employing inductively coupled plasma-mass spectroscopy, and the oxidation states of copper on Si wafer surface, employing X-ray photoelectron spectroscopy. It was determined that the reaction kinetics is first order with respect to both HF and oxygen concentrations. A kinetic scheme involving reduction of oxygen and oxidation of $\mathrm{Cu}^{0}$ and $\mathrm{Cu}^{1+}$ is proposed, which is consistent with the experimentally determined reaction kinetic orders and the observed deposition of undesired copper residues on semiconductor wafers during the cleaning process.

(C) 2010 The Electrochemical Society. [DOI: 10.1149/1.3446816] All rights reserved.

Manuscript submitted January 26, 2010; revised manuscript received April 23, 2010. Published June 11, 2010.

As advanced microprocessors have employed smaller geometric features in the pursuit of low power consumption, increased speed, and high integration density, the traditional interconnect material aluminum $^{1,2}$ has been replaced by copper. Due to its high conductivity, $\mathrm{Cu}$ as an interconnect material has been actively explored for many years ${ }^{3,4}$ but its feasibility as a production technology was demonstrated in $1997^{5,6}$ through a process known as dual damascene (DD). Soon thereafter, the method became the process of record in high volume production of advanced microprocessors. ${ }^{7}$

The introduction of copper in semiconductor devices has brought attention to the phenomenon of thin-film corrosion that must be circumvented for optimal device performance, reliability, and longevity. The presence of copper-rich residues on the wafer surface, after wet clean steps using non-copper compatible chemistry in a semiconductor manufacturing environment, was detected and reported by Mistkawi et al. ${ }^{8}$ These results underscored the need for a better understanding of wet etch clean chemistries for the integration of DD patterning of copper interconnects. In our previous work, ${ }^{8}$ we studied the phenomena of copper corrosion/dissolution during cleaning process, which led to the redeposition/precipitation of undesired copper and copper-rich residues onto the wafer surface, affecting the yield and reliability of devices. . $^{-12}$

The objective of the study reported herein is to investigate the kinetics of copper thin-film corrosion/dissolution in an aqueous solution containing $\mathrm{HF}$ and organic compounds and its relevance to the DD process of copper interconnects. Such solutions are commonly used in the industry for post-plasma-etch cleaning. The kinetics with respect to dissolved oxygen (DO) $\left(\mathrm{O}_{2}^{\mathrm{dis}}\right)$ and HF concentrations is presented.

\section{Experimental}

Substrate.- The experiments were performed using copper on blanket silicon wafers $(\mathrm{Cu} / \mathrm{Si})$ substrate. The copper film was uniformly deposited using typical industry electroplating equipment ${ }^{5,13}$ followed by a chemical mechanical planarization step to closely mimic the actual $\mathrm{Cu}$ surface during the DD process. The thickness of the $\mathrm{Cu}$ film was $\sim 400 \mathrm{~nm}$ as determined by a four-point probe method (surface resistivity meter, Guardian Manufacturing Inc., model SRM-232) and cross section scanning electron microscopy.

Surface preparation.- Before proceeding with dissolution experiments, surface treatment with 0.49 wt $\% \mathrm{HF}$ was carried out to ensure a clean surface. A set of screening experiments to investigate optimal dip time in HF solution for surface cleaning was conducted.

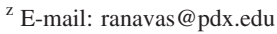

A 1 min HF treatment was appropriate. This pretreatment rendered a clean surface on which the native copper oxide was partially removed to expose a clean elemental copper surface. Longer exposure $(\approx 5 \mathrm{~min})$ of the wafer to HF did not alter the X-ray photoelectron spectroscopy (XPS) spectra, which exhibited peaks due to $\mathrm{Cu}(\mathrm{I})$ and $\mathrm{Cu}(0)(8)$ (Fig. 1 inset) and no peaks due to $\mathrm{F}$ (Fig. 1), which were expected in the region of $685-690 \mathrm{eV}^{14}$

Cleaning solution.- The dissolution experiments were performed utilizing a semiconductor cleaning chemical solution (EG3) supplied by Ashland Chemicals, which was composed of 93 wt \% ethylene glycol, $\sim 4 \mathrm{wt} \%$ ammonium fluoride, $0.033 \mathrm{wt} \% \mathrm{HF}$, and $\sim 3$ wt $\%$ water. The cleaning solution had $\mathrm{pH} 6.8$. All experiments were carried out at room temperature $\left(21^{\circ} \mathrm{C}\right)$.

Dissolution experiments. - Dissolution experiments were carried out using $16 \mathrm{~cm}^{2}(4 \times 4 \mathrm{~cm})$ copper/silicon wafer coupons in a $300 \mathrm{~mL}$ volume of stirred aerated, deaerated, or non-deaerated cleaning solutions. Deaeration was achieved by bubbling nitrogen, whereas aeration was achieved by bubbling air through the solution. DO concentration measurements were performed using a digital oxygen meter (Traceable DO meter, Control Co., model RS-232) at $\sim 1 \mathrm{~cm}$ from the air-water interface.

Aliquots from the cleaning solution containing the copper wafer were collected at approximately the same depth for inductively coupled plasma-mass spectroscopy (ICP-MS) analysis at specific intervals to determine copper concentrations. Experiments were performed in three replicates to ensure reproducibility. ICP-MS measurements were performed using Agilent 7500CS.

\section{Results and Discussion}

In a recent paper, ${ }^{8}$ we discussed the electrochemical corrosion process of copper-coated silicon wafers in the cleaning solutions employed in the present work. The corrosion rate depended on the concentration of DO from air (non-deareated solution); an increase in corrosion rate was observed with an increase in oxygen concentration in the cleaning solution.

To probe further how the oxidizing agents, such as oxygen from the air, can affect the corrosion process, we investigated timedependent copper concentration, as shown in Fig. 2a. Here, an initial increase in the copper concentration was followed by significantly slower rates of dissolution at later times. This trend is independent of the DO concentration. The concentration of copper at longer times is dependent on the DO concentration (see Fig. 2b). Therefore, we also measured the concentration of oxygen as a function of time and the number of wafers. The objective was to find out if a steadystate (SS) concentration of $\mathrm{O}_{2}$ (i.e., $d\left[\mathrm{O}_{2}\right] / d t=0$ ) is reached in the cleaning solution. Figure 3 depicts the DO concentration for clean- 


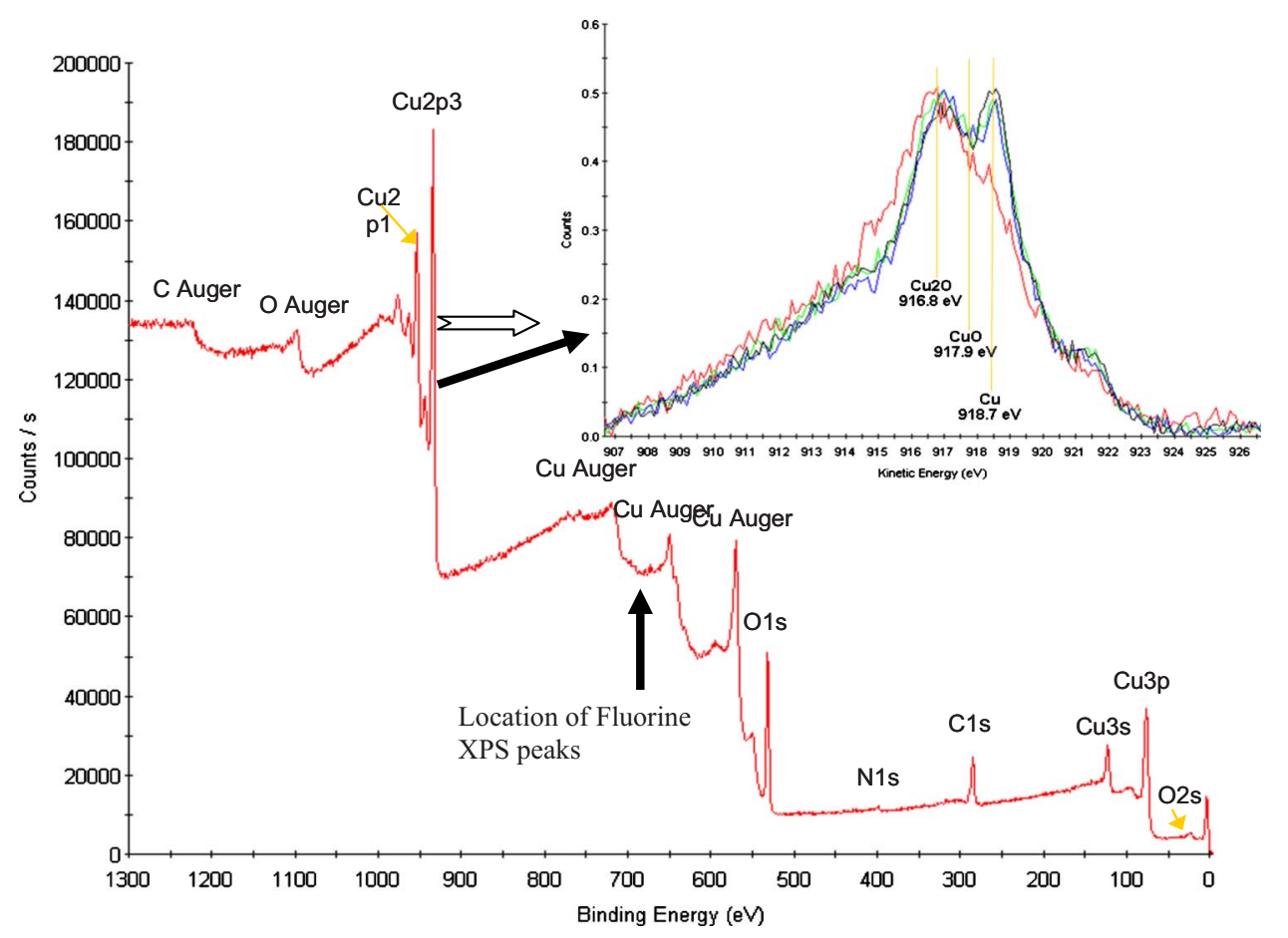

Figure 1. (Color online) Survey XPS spectra from a clean copper-coated wafer surface, lacking fluorine peaks in 685-690 $\mathrm{eV}$ region. The region where oxidation states of copper can be identified (yellow vertical lines) is shown in the inset. It shows XPS spectra from wafers treated with different cleaning solutions: Control (red), aqueous HF (blue), and organic cleaning solution (green).

ing solutions. The results show that within 50 min, a timescale comparable to the initial surge in copper dissolution shown in Fig. 2, the corresponding oxygen concentration in the cleaning solution decreases and reaches an SS. When two more wafers were immersed in the same solution at $t=8700 \mathrm{~min}$, a further decline in $\mathrm{O}_{2}$ concentration occurred on a similar timescale, reaching a new lower SS of oxygen concentration $(\approx 1.5 \mathrm{ppm})$. Therefore, the corrosion process involves oxygen participation, as is further demonstrated.

The essential component of the cleaning solution is HF. It can attack exposed oxide surfaces of copper and silicon, thereby functioning as a cleaning agent, provided the duration of cleaning is precisely controlled. Thermodynamically, the free energy of formation for $\mathrm{Cu}^{2+}$ from $\mathrm{Cu}^{0}$ or $\mathrm{Cu}^{+}$is negative. However, in our earlier
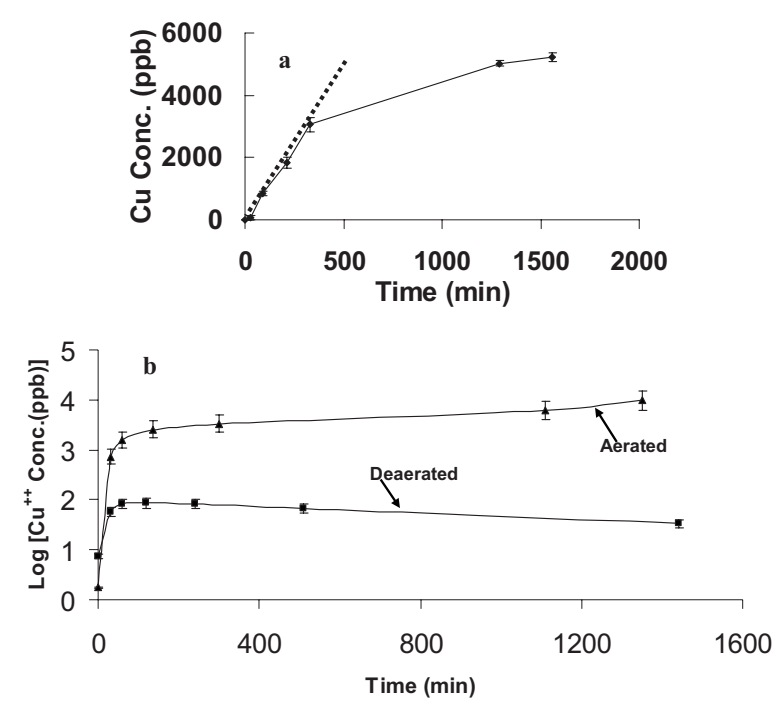

Figure 2. (a) $\mathrm{Cu}$ dissolution in non-deaerated samples. The dashed lines indicate the initial copper dissolution rate. (b) A log of copper concentration in ppb vs time for aerated and deaerated cleaning solutions is shown. The $\mathrm{O}_{2}^{\text {dis }}$ concentrations were $8.9,4.5$, and $0.6 \mathrm{mg} / \mathrm{L}$ in the aerated, non-deareated, and deaerated solutions, respectively. electrochemical studies, $\mathrm{H}_{2} \mathrm{O}_{2}$ treated copper surface forms a $\mathrm{CuO}$ film that confers a degree of passivity to the copper film, whereas aerated and non-deareated solutions generally corrode at an appreciable rate. ${ }^{8}$

A simple electrochemical model of the dissolution process is proposed in Fig. 4. It depicts a reduction of oxygen coupled with oxidation of $\mathrm{Cu}^{0}$ that can lead to the formation of $\mathrm{Cu}^{2+}$ species (through disproportionation) in the cleaning solution. Given that the

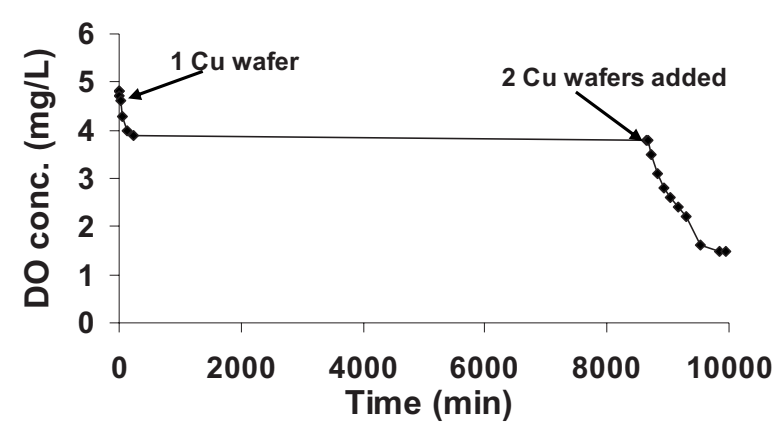

Figure 3. Temporal evolution of oxygen concentration in the cleaning solution as a function of time and $\mathrm{Cu}$ surface area are shown.

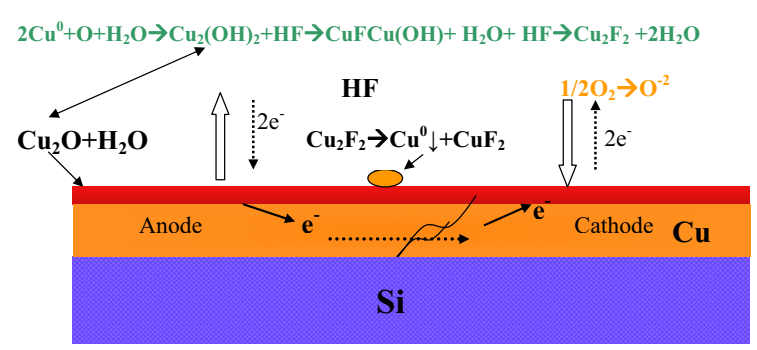

Figure 4. (Color online) A simple electrochemical model of the dissolution process showing the reduction of oxygen coupled with oxidation of $\mathrm{Cu}^{0}$ that leads to the formation of $\mathrm{Cu}^{2+}$ species in the cleaning solution. 
cleaning solution contains 3-4\% water and ppb level concentration of copper species in the cleaning solution, we expect the formation of mainly ionic species, although we cannot rule out the possibility of forming neutral ion pairs at higher concentrations. More specifically, we write the redox reactions involved in the dissolution of copper from a wafer substrate:

Reduction reaction

$$
2 \mathrm{e}+\frac{1}{2} \mathrm{O}_{2} \rightarrow \mathrm{O}^{2-}
$$

Oxidation reaction

$$
2 \mathrm{Cu}^{0} \rightarrow 2 \mathrm{Cu}^{+}+2 \mathrm{e}
$$

Net reaction

$$
2 \mathrm{Cu}^{0}+\frac{1}{2} \mathrm{O}_{2} \rightarrow 2 \mathrm{Cu}^{1+}+\mathrm{O}^{2-} \rightarrow \mathrm{Cu}_{2} \mathrm{O}+\mathrm{H}_{2} \mathrm{O} \rightarrow \mathrm{Cu}_{2}(\mathrm{OH})_{2}
$$

Given that our XPS data always show the presence of $\mathrm{Cu}^{1+}$ species (Fig. 1 and Ref. 8), oxidation of $\mathrm{Cu}^{0} \rightarrow \mathrm{Cu}^{1+}$ through the formation of hydrated cuprous oxide might be a route toward the copper dissolution process. Copper hydroxide may exist in the form of an ion pair. Our XPS data of the copper surface could not be collected during the active cleaning procedure, thus making it difficult to ascertain chemical species present during the cleaning. Likewise, the electrosprayed ICP-MS evaluation of the copper concentration only reports the concentration of positively charged copper species. Our working hypothesis here is that the final copper species remaining in the cleaning solution is $\mathrm{Cu}^{2+}$, created by the oxidation of $\mathrm{Cu}^{+}$or $\mathrm{Cu}^{0}$. The most likely anion interacting with $\mathrm{Cu}^{2+}$ species is fluoride ion. Here, we estimate the solubility of the cupric ions in the cleaning solution by noting that the aqueous solubility of $\mathrm{CuF}_{2}$ at room temperature is $750 \mathrm{ppm}^{15}$ As the cleaning solution contains protic solvent ethylene glycol (93\%), 3\% water, and 4\% $\mathrm{NH}_{4} \mathrm{~F}$ (which reduces the solubility of $\mathrm{CuF}_{2}$ through common ion effect), the observed $2-10 \mathrm{ppm}$ copper concentration in the long time limit is consistent with the aqueous solubility data. However, the solubility of $\mathrm{Cu}(\mathrm{I})$ species such as $\mathrm{Cu}_{2} \mathrm{~F}_{2}{ }^{16}(\mathrm{CuF})$ or $\mathrm{Cu}_{2}(\mathrm{OH})_{2}(\mathrm{CuOH})$ is likely to be far lower (perhaps in the sub-ppb level) following the general trend in copper halide/hydroxide solubility. ${ }^{17,18}$ We consider below the thermodynamic and kinetic aspects for the observed dissolution of copper into the cleaning solution.

Thermodynamically, the following stoichiometrically balanced reaction steps are energetically feasible

Anaerobic reactions: $\mathrm{Cu}_{2} \mathrm{O}+2 \mathrm{HF} \rightarrow \mathrm{Cu}_{2} \mathrm{~F}_{2}+\mathrm{H}_{2} \mathrm{O}$

$$
\mathrm{Cu}_{2} \mathrm{~F}_{2} \rightarrow \mathrm{Cu}^{0}+\mathrm{CuF}_{2}
$$

Aerobic reactions: $2 \mathrm{Cu}^{0}+\frac{1}{2} \mathrm{O}_{2}+\mathrm{H}_{2} \mathrm{O} \rightarrow \mathrm{Cu}_{2}(\mathrm{OH})_{2}+2 \mathrm{HF}$

$$
\begin{aligned}
\rightarrow \mathrm{Cu}_{2} \mathrm{~F}_{2}+2 \mathrm{H}_{2} \mathrm{O} & \\
\mathrm{Cu}_{2} \mathrm{~F}_{2}+2 \mathrm{HF}+\frac{1}{2} \mathrm{O}_{2} \rightarrow 2 \mathrm{CuF}_{2}+\mathrm{H}_{2} \mathrm{O} & \\
\mathrm{Cu}^{0}+\mathrm{CuF}_{2} & \\
\mathrm{Cu}_{2} \mathrm{~F}_{2} \backslash & \\
& +2 \mathrm{HF}+\frac{1}{2} \mathrm{O}_{2} \rightarrow 2 \mathrm{CuF}_{2}+\mathrm{H}_{2} \mathrm{O}
\end{aligned}
$$

The first step accounts for the fact that the copper surface has a native thin film of cuprous oxide. The second step suggests a disproportionation of $\mathrm{Cu}(\mathrm{I})$ salts by analogy with other copper(I) halides in protic solvents, ${ }^{17}$ although it has never been firmly established in $\mathrm{Cu}_{2} \mathrm{~F}_{2}$. Disproportionation is consistent with our observed copper-rich residues on the dielectric surfaces, although it does not prove its occurrence. ${ }^{8}$ In this reaction scheme, we emphasize the role of $\mathrm{O}_{2}$ in the corrosion process to account for the DO-dependent copper dissolution presented in Fig. 2 and 3 through the formation of $\mathrm{Cu}_{2}(\mathrm{OH})_{2}$ and its reaction with HF. The rationale for this step is as follows. Given that $K_{\mathrm{sp}}$ for the cuprous hydroxide species coexisting with cuprous oxide and water is about $10^{-14}$ and, hence, at the most, a sub-ppb level concentration of copper can be contributed by it to the cleaning solution at equilibrium (i.e., long time limit). The contribution of cupric hydroxide, should it form, would be even lower because its $K_{\mathrm{sp}}$ is about $10^{-19}$ or lower. ${ }^{18}$ The solubility data for $\mathrm{Cu}_{2} \mathrm{~F}_{2}{ }^{19}$ (or $\mathrm{CuF}$ ) are not available, but by extrapolating the solubility trends for other copper halides, ${ }^{17}$ we expect an even lower contribution of copper in the cleaning process from cuprous fluoride. Therefore, by default, the reaction of $\mathrm{HF}$ with $\mathrm{Cu}^{0}$ or $\mathrm{Cu}^{1+}$ species must be invoked (as discussed above and later) to account for the observed high copper concentrations ( $8-10 \mathrm{ppm})$, at a slightly acidic (6.8) $\mathrm{pH}$ of the cleaning solution.

To develop a molecular mechanism for the kinetics of copper dissolution, we focus on the short-time behavior. This is directly relevant for semiconductor processing, as typically wafers are expected to be cleaned in less than $5 \mathrm{~min}$. To study the kinetics in this time region, we employed the method of initial rates, where $d\left[\mathrm{Cu}^{2+}\right] / d t{ }^{\mathrm{d}}$ was determined by drawing a tangent to the copper concentration vs the $t$ curve in the limit $t \rightarrow 0$ (see Fig. 2a). Under these conditions a general rate equation for the appearance of $\left[\mathrm{Cu}^{2+}\right]$ (assuming that ultimately it is the most soluble and chemically stable) species in the cleaning solution can be written as

$$
\frac{d\left[\mathrm{Cu}^{2+}\right]}{d t}=k\left[\mathrm{O}_{2}^{\mathrm{dis}}\right]^{n}[\mathrm{HF}]^{m}
$$

Here, $n$ and $m$ are the reaction orders with respect to $\mathrm{DO}\left(\mathrm{O}_{2}^{\mathrm{dis}}\right)$ and $\mathrm{HF}$ concentration, respectively. Figure 5 a shows the copper dissolution rate as a function of the $\mathrm{O}_{2}^{\text {dis }}$ concentration in a fixed HF concentration (note dissolution rates are in $\mathrm{ppb} / \mathrm{min}$, whereas the concentration of $\mathrm{HF}$ is in the high $100 \mathrm{~s}$ of ppm range). Similarly for fixed oxygen concentration ( $<10 \mathrm{ppm}$ range) in well-stirred cleaning solutions, the dissolution rate was determined as a function of HF concentration (Fig. 5b). The slopes of the best fitted lines yielded values for $n \approx m \approx 1.0 \pm 0.1$. Also, plots of $\ln \left(\mathrm{O}_{2}-\mathrm{O}_{2}^{\mathrm{SS}}\right)$ (where $\mathrm{O}_{2}^{\text {SS }}$ denotes the SS concentration of $\mathrm{O}_{2}^{\text {dis }}$ ) vs time were linear (not shown), implying a first-order kinetic rate process for the decrease in the dissolved $\mathrm{O}_{2}$ concentration for the data presented in Fig. 3.

A plausible set of elementary kinetic reactions are presented below

$$
\mathrm{O}_{2}^{\mathrm{dis}} \rightleftarrows \mathrm{O}_{2}^{\text {ads }} \quad k_{0}^{\mathrm{eq}} \quad \text { adsorption }
$$

$$
\mathrm{O}_{2}^{\mathrm{ads}} \stackrel{k_{1}}{\rightarrow} 2 \mathrm{O}^{\mathrm{ads}} \quad \text { dissociation }
$$

$2 \mathrm{Cu}+\mathrm{O}^{\text {ads }}+\mathrm{H}_{2} \underset{k_{-2}}{\stackrel{\mathrm{O}_{2}}{\rightleftarrows}} \mathrm{Cu}_{2}(\mathrm{OH})_{2} \quad k_{2}^{\text {eq }}$ redox reaction (passivation)

$$
\mathrm{Cu}_{2}(\mathrm{OH})_{2}+\mathrm{HF} \rightarrow \mathrm{ku}(\mathrm{OH}) \mathrm{CuF}+\mathrm{H}_{2} \mathrm{O} \quad \text { intermediate species }
$$

$$
\mathrm{Cu}(\mathrm{OH}) \mathrm{CuF}+\mathrm{HF} \stackrel{k_{4}}{\rightarrow} \mathrm{Cu}_{2} \mathrm{~F}_{2}+\mathrm{H}_{2} \mathrm{O} \quad \text { intermediate species }
$$

\footnotetext{
${ }^{\mathrm{d}}$ Here the copper concentration is the concentration as determined by ICP-MS.
} 
a) kinetic order with respect to Oxygen $0.9+-0.1$

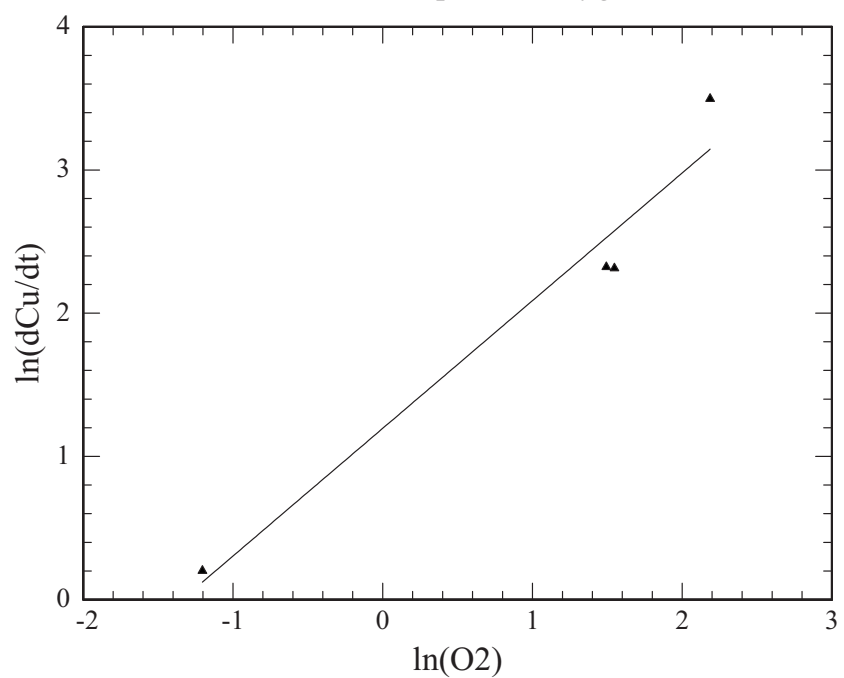

b)

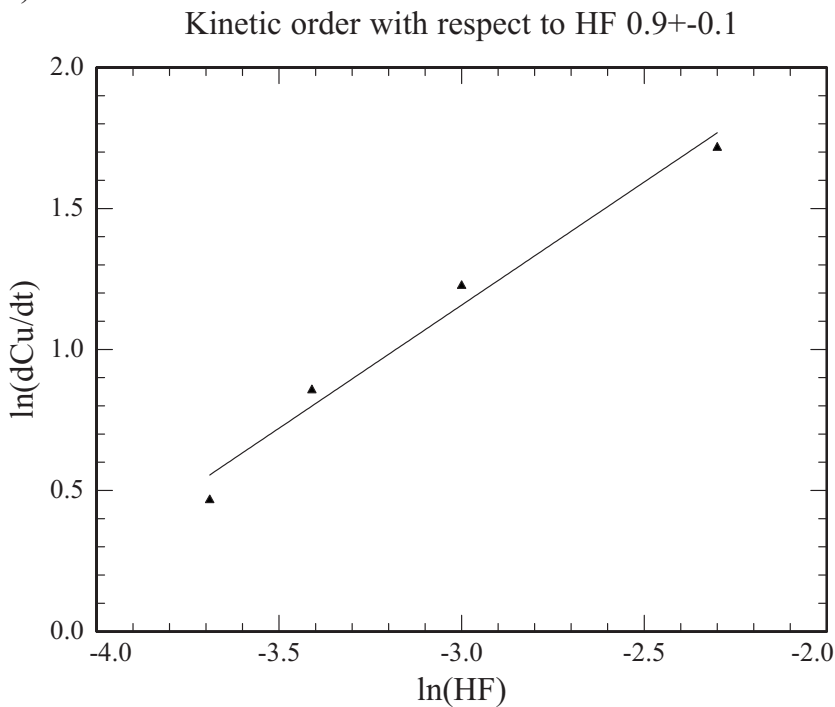

Figure 5. An ln-ln plot of initial copper dissolution rate vs (a) DO and (b) HF concentration allows determination of kinetic orders. The copper dissolution rate is in $\mathrm{ppb} / \mathrm{min}$, whereas the concentration units for $\mathrm{DO}$ and $\mathrm{HF}$ are in $\mathrm{mg} / \mathrm{L}$ and percentage concentration, respectively.

$$
\mathrm{Cu}_{2} \mathrm{~F}_{2} \stackrel{k_{5}}{\rightarrow} \mathrm{Cu}^{0}+\mathrm{CuF}_{2} \text { disproportionation }
$$

The corresponding kinetic analysis is detailed in the Appendix, along with the rationale for selecting these elementary reaction steps and the intermediates. The main simplification we make here is that all the $\mathrm{Cu}^{1+}$ species as well as atomic oxygen are subjected to the SS approximation. In this limit, a simple rate expression for copper dissolution may be given as

$$
\frac{d\left[\mathrm{Cu}^{2+}\right]}{d t}=k_{3}\left[\mathrm{Cu}_{2}(\mathrm{OH})_{2}\right][\mathrm{HF}]=\frac{2 k_{0}^{\mathrm{eq}} k_{1} k_{2}^{\mathrm{eq}} k_{3}\left[\mathrm{O}_{2}^{\mathrm{dis}}\right][\mathrm{HF}]}{\left(k_{2}-k_{-2} k_{2}^{\mathrm{eq}}\right)}
$$

In this analysis, the kinetic rate of adsorbed $\mathrm{O}_{2}$ dissociation as well as the rate of $\mathrm{Cu}_{2}(\mathrm{OH})_{2}{ }^{18}$ formation provide plausible ratedetermining steps. The expression in Eq. 5 is consistent with the observed rate law, although we have not detected the postulated intermediates such as $\mathrm{Cu}_{2} \mathrm{~F}_{2}{ }^{19}$ or $\mathrm{Cu}(\mathrm{OH}) \mathrm{CuF}$ in our experimental work. If the SS approximation is valid, their concentrations are ex- pected to be too low. In view of these considerations, we have not further modeled the detailed kinetics that could include the second oxidation step involving oxygen for the $\mathrm{Cu}^{+}$species (see Eq. 2 above) as it would entail postulating additional intermediates (e.g., $\mathrm{H}_{2} \mathrm{Cu}_{2} \mathrm{~F}_{4}$ ), etc. Nonetheless, if the branching ratio of $\mathrm{Cu}_{2} \mathrm{~F}_{2}$ favors disproportionation, then the kinetic analysis presented above becomes applicable as the molecular level mechanistic model of copper corrosion and deposition of undesired copper-rich residues on the dielectric surfaces in the HF containing cleaning solution.

Finally, we compare our findings with an early study of copper electrolyte interface in aqueous medium by Chan et al. ${ }^{20}$ In this classic work, surface oxide formation was detected in basic/neutral $\mathrm{pH}$ conditions, whereas in strongly acidic conditions, the formation $\mathrm{Cu}-\mathrm{X}$ (where $\mathrm{X}$ is an anion) species was observed. ${ }^{21-24}$ Chan et al. observed that even in weakly acidic conditions adsorbed oxygen species, as opposed to oxide formation, were observable in their surface enhanced Raman studies. It is this observation that led us to postulate steps $4 \mathrm{a}$ and $4 \mathrm{~b}$. However, near the neutral $\mathrm{pH}$, these authors suggest both formation of oxide as well as halides of $\mathrm{Cu}^{1+}$. In this scenario, copper oxidation is facilitated by halides. The following sequences can be suggested for anodic dissolution of copper by fluoride ions based on their work

$$
\begin{gathered}
2 \mathrm{Cu}+2 \mathrm{~F}^{-} \stackrel{k_{2}}{\rightarrow} \mathrm{Cu}_{2} \mathrm{~F}_{2}+2 \mathrm{e} \\
\mathrm{Cu}_{2} \mathrm{~F}_{2} \rightarrow \mathrm{Cu}^{0}+\mathrm{CuF}_{2} \\
\mathrm{O}^{\mathrm{ads}}+2 \mathrm{H}^{+}+2 \mathrm{e} \rightarrow \mathrm{H}_{2} \mathrm{O} \\
2 \mathrm{Cu}+2 \mathrm{HF} \rightarrow \mathrm{H}_{2} \mathrm{Cu}_{2} \mathrm{~F}_{2} \\
\mathrm{H}_{2} \mathrm{Cu}_{2} \mathrm{~F}_{2}+\mathrm{O}^{\mathrm{ads}} \rightarrow \mathrm{H}_{2} \mathrm{O}+\mathrm{CuF}_{2}+\mathrm{Cu}^{0}
\end{gathered}
$$

In this scheme, copper oxidation is initiated by $\mathrm{F}^{-}$and the compensating oxygen reduction involving protons is postulated. This mechanism does not lead to a first-order kinetics with respect to $\mathrm{HF}^{-}$ or $\mathrm{F}^{-}$(note Eq. 6d). Also, Eq. 6a depends on fluoride ion concentration, which is in excess in the cleaning solution $\left(4 \% \mathrm{NH}_{4} \mathrm{~F}\right)$ so that the dissolution rate would be controlled by the adsorbed oxygen concentration and $\left[\mathrm{H}^{+}\right]$(Eq. 6c) is raised to power 2 (i.e., the order with respect to HF concentration would be 2 ; see Eq. $6 \mathrm{~d}$ ). Given that our cleaning solution exhibits a $\mathrm{pH}$ that is nearly neutral $(\mathrm{pH} 6.8)$, the formation of $\mathrm{Cu}_{2}(\mathrm{OH})_{2}$ (i.e., Eq. 4c) is expected to dominate the dissolution kinetics. This is also consistent with the weak passivation observed in potentiodynamic studies. ${ }^{8}$

A more detailed verification of these models would require systematic studies that involve variation in $\mathrm{pH}$ of the cleaning solution to observe differing kinetic exponents $n$ and $m$ consistent with reaction sequences presented in Eq. 6. Such studies are beyond the scope of the present investigation, which focuses on copper surface dissolution using the commercial cleaning solution.

\section{Conclusions}

A simple kinetic model is proposed for the copper dissolution during wet chemical cleaning process. It predicts experimentally observed first-order kinetics with respect to DO and HF, the two key ingredients involved in corrosion of copper. If DO is eliminated, the rate of copper corrosion can be suppressed.

Intel Corporation assisted in meeting the publication costs of this article.

\section{Appendix}

Potential elementary reactions

$$
\mathrm{O}_{2}^{\text {dis }} \rightleftarrows \mathrm{O}_{2}^{\text {ads }} \quad k_{0}^{\text {eq }}=\frac{\left[\mathrm{O}_{2}^{\text {ads }}\right]}{\left[\mathrm{O}_{2}^{\text {dis }}\right]}
$$

$$
\stackrel{\mathrm{O}_{2}}{k_{1}} \rightarrow 2 \text { Oads } \frac{d\left[\mathrm{O}^{\mathrm{ads}}\right]}{d t}=2 k_{1}\left[\mathrm{O}_{2}^{\mathrm{ads}}\right]+k_{-2}\left[\mathrm{Cu}_{2}(\mathrm{OH})_{2}\right]-k_{2}\left[\mathrm{O}^{\mathrm{ads}}\right]=0
$$




$$
\begin{gathered}
2 \mathrm{Cu}+\mathrm{O}^{\mathrm{ads}}+\mathrm{H}_{2} \mathrm{O} \underset{k_{-2}}{\stackrel{k_{2}}{\rightleftarrows}} \mathrm{Cu}_{2}(\mathrm{OH})_{2} \quad k_{2}^{\mathrm{eq}}=\frac{\left[\mathrm{Cu}_{2}(\mathrm{OH})_{2}\right]}{\left[\mathrm{O}^{\mathrm{ads}}\right]}=\frac{k_{2}\left[\mathrm{Cu}_{2}(\mathrm{OH})_{2}\right]}{2 k_{1}\left[\mathrm{O}_{2}^{\mathrm{ads}}\right]+k_{-2}\left[\mathrm{Cu}_{2}(\mathrm{OH})_{2}\right]} \\
=\frac{k_{2}\left[\mathrm{Cu}_{2}(\mathrm{OH})_{2}\right]}{2 k_{1} k_{0}^{\mathrm{eq}}\left[\mathrm{O}_{2}^{\mathrm{dis}}\right]+k_{-2}\left[\mathrm{Cu}_{2}(\mathrm{OH})_{2}\right]} \\
\therefore\left[\mathrm{Cu}_{2}(\mathrm{OH})_{2}\right]=\frac{2 k_{1} k_{0}^{\mathrm{eq}}\left[\mathrm{O}_{2}^{\mathrm{dis}}\right]}{\left(\frac{k_{2}}{k_{2}^{\mathrm{eq}}}-k_{-2}\right)}=k^{\prime}\left[\mathrm{O}_{2}^{\text {dis }}\right]
\end{gathered}
$$

Noting that the order with respect to oxygen concentration is unity, we postulate two reaction steps for the generation of atomic oxygen on the surface as opposed to a one-step reversible dissociative adsorption of dissolved $\left[\mathrm{O}_{2}\right]$. The one-step model predicts a kinetic order of $\frac{1}{2}$ with respect to DO, inconsistent with the experimentally observed value. Furthermore, we assume that the concentration of the dissociatively adsorbed atomic $\mathrm{O}$ is in the SS, and quasi-equilibria are established rapidly for the first and third reactions. If the reaction of the adsorbed oxygen with copper is made irreversible as opposed to reversible, then under the conditions of SS approximation for the intermediates $\left(\mathrm{Cu}_{2}[\mathrm{OH}]_{2},[\mathrm{CuOHCuF}]\right.$, and $\left.\left[\mathrm{Cu}_{2} \mathrm{~F}_{2}\right]\right)$ the initial $\mathrm{Cu}^{2+}$ dissolution rate in the cleaning solution becomes independent of HF concentration, whereas experimentally we noted a first-order dependence with respect to $\mathrm{HF}$ concentration.

Intuitively, one expects $\mathrm{Cu}_{2}(\mathrm{OH})_{2}$ concentration in the solution to be very small, way below the ppb level $\mathrm{Cu}^{2+}$ concentration observed during the initial stages of reaction. Unfortunately, such a sub-ppb level concentration makes the detection of this species, as well as other intermediates described below, difficult in practice, so the sequence of reactions outlined above should be treated as a plausible but not confirmatory sequence of elementary reactions. The reaction steps given below consider the generation of $\mathrm{Cu}^{2+}$ species in solution through the attack of $\mathrm{HF}$ on $\mathrm{Cu}_{2}(\mathrm{OH})_{2}$

$$
\mathrm{Cu}_{2}(\mathrm{OH})_{2}+\mathrm{HF} \stackrel{k_{3}}{\rightarrow} \mathrm{Cu}(\mathrm{OH}) \mathrm{CuF}+\mathrm{H}_{2} \mathrm{O}
$$

$$
\begin{gathered}
\frac{d[\mathrm{Cu}(\mathrm{OH}) \mathrm{CuF}]}{d t}=k_{3}\left[\mathrm{Cu}_{2}(\mathrm{OH})_{2}\right][\mathrm{HF}]-k_{4}[\mathrm{Cu}(\mathrm{OH}) \mathrm{CuF}][\mathrm{HF}]=0 \\
\mathrm{Cu}(\mathrm{OH}) \mathrm{CuF}+\mathrm{HF} \rightarrow \mathrm{Cu}_{2} \mathrm{~F}_{2}+\mathrm{H}_{2} \mathrm{O} \\
\frac{d\left[\mathrm{Cu}_{2} \mathrm{~F}_{2}\right]}{d t}=k_{4}[\mathrm{Cu}(\mathrm{OH}) \mathrm{CuF}][\mathrm{HF}]-k_{5}\left[\mathrm{Cu}_{2} \mathrm{~F}_{2}\right]=0 \\
k_{5} \mathrm{Cu}_{2} \mathrm{~F}_{2} \rightarrow \mathrm{Cu}^{0}+\mathrm{CuF}_{2} \\
\frac{d\left[\mathrm{Cu}^{2+}\right]}{d t}=k_{5}\left[\mathrm{Cu}_{2} \mathrm{~F}_{2}\right]=k_{4}[\mathrm{Cu}(\mathrm{OH}) \mathrm{CuF}][\mathrm{HF}]=k_{3}\left[\mathrm{Cu}_{2}(\mathrm{OH})_{2}\right][\mathrm{HF}]
\end{gathered}
$$

Again, the choice of two stepwise reactions is presented rather than a single termolecular reaction involving two HF molecules reacting with $\mathrm{Cu}_{2}(\mathrm{OH})_{2}$ to yield $\mathrm{Cu}_{2} \mathrm{~F}_{2}$ directly. This choice was made to rationalize the observed first-order dependence of copper dissolution rate with respect to $\mathrm{HF}$ concentration. The above cascade of reactions assumes the formation of $\mathrm{Cu}(\mathrm{OH}) \mathrm{CuF}$ and $\mathrm{Cu}_{2} \mathrm{~F}_{2}$ species. Experimentally, we have no evidence for the formation of either species. We make the SS approximation for these latter species by assuming their high reactivity that could lead to their very low concentrations. Substituting for the $\left[\mathrm{Cu}_{2}(\mathrm{OH})_{2}\right]$ concentration

$$
\frac{d\left[\mathrm{Cu}^{2+}\right]}{d t}=k_{3}\left[\mathrm{Cu}_{2}(\mathrm{OH})_{2}\right][\mathrm{HF}]=\frac{2 k_{1} k_{3} k_{0}^{\mathrm{eq}}\left[\mathrm{O}_{2}^{\mathrm{dis}}\right][\mathrm{HF}]}{\left(\frac{k_{2}}{k_{2}^{\mathrm{eq}}}-k_{-2}\right)}=\frac{2 k_{0}^{\mathrm{eq}} k_{1} k_{2}^{\mathrm{eq}} k_{3}\left[\mathrm{O}_{2}^{\mathrm{dis}}\right][\mathrm{HF}]}{\left(k_{2}-k_{-2} k_{2}^{\mathrm{eq}}\right)}
$$

\section{References}

1. J. G. Ryan, R. M. Geffken, N. R. Poulin, and J. R. Paraszczak, IBM J. Res. Dev. 39, 371 (1995)

2. M. Brillouet, in Materials for Advanced Metallization, MAM'97 Abstracts Booklet, European Workshop, p. 36, IEEE (1997).

3. J. Li, Y. Shacham-Diamand, and J. W. Mayer, Mater. Sci. Rep., 9, 1 (1992).

4. S. P. Murarka and S. W. Hymes, Crit. Rev. Solid State Mater. Sci., 20, 87 (1995)

5. J. H. D. Edelstein, R. Goldblatt, W. Cote, C. Uzoh, N. Lustig, P. Roper, T. McDevitt, W. Motsiff, A. Simon, J. Dukovic, et al., Tech. Dig. - Int. Electron Devices Meet., 1997, 774

6. A. V. G. S. Venketesan, V. Misra, B. Smith, R. Islam, J. Cope, B. Wilson, D. Tuttle, R. Cardwell, S. Anderson, M. Angyal, et al., Tech. Dig. - Int. Electron Devices Meet., 1997, 769.

7. N. Rohrer, C. Akrout, M. Canada, D. Cawthron, B. Davari, R. Floyd, S. Geissler, R. Goldblatt, R. Houle, P. Kartschoke, et al., Dig. Tech. Pap.-IEEE Int. Solid-State Circuits Conf., 1998, 240.

8. N. G. Mistkawi, M. A. Hussein, M. Ziomek-Moroz, and S. B. Rananavare, $J$ Electrochem. Soc., 157, C24 (2010)

9. J. S. Kim, H. Morita, J. D. Joo, and T. Ohmi, J. Electrochem. Soc., 144, 3275 (1997).

10. G. J. Norga, M. Platero, K. A. Black, A. J. Reddy, J. Michel, and L. C. Kimerling, J. Electrochem. Soc., 144, 2801 (1997).

11. L. Mouche, F. Tardif, and J. Derrien, J. Electrochem. Soc., 142, 2395 (1995).

12. G. Li, E. A. Kneer, B. Vermeire, H. G. Parks, S. Raghavan, and J. S. Jeon, J. Electrochem. Soc., 145, 241 (1998).

13. P. Singer, Semicond. Int., 21, 90 (1998).

14. G. G. Totir, G. S. Chottiner, C. L. Gross, and D. A. Scherson, J. Electroanal Chem., 532, 151 (2002).

15. Handbook of Inorganic Compounds, D. L. P. S. L. Phillips, Editor, p. 143, CRC Press, Boca Raton, FL (1995)

16. V. V. Richter, A Textbook of Inorganic Chemistry, pp. 335-336, P. Blakiston's Son \& Co., Philadelphia (1892)

17. S. Ahrland, Pure Appl. Chem., 62, 2077 (1990).

18. R. M. Garrels, Geochim. Cosmochim. Acta, 5, 153 (1954).

19. A. M. Comey and D. A. Hahn, Dictionary of Chemical Solubilities (Inorganic), p. 1141, MacMillan, New York (1921).

20. H. Y. H. Chan, C. G. Takoudis, and M. J. Weaver, J. Phys. Chem. B, 103, 357 (1999).

21. D. B. Hibbert, S. Richards, and V. Gonzalves, Corros. Sci., 30, 367 (1990).

22. E. D'Elia, O. E. Barcia, O. R. Mattos, N. Pebere, and B. Tribollet, J. Electrochem. Soc., 143, 961 (1996).

23. A. G. Zelinsky, B. Y. Pirogov, and O. A. Yurjev, Corros. Sci., 46, 1083 (2004).

24. Z. Zembura and J. Bugajski, Corros. Sci., 21, 69 (1981). 